Article

\title{
Assessment of Affinity towards Diversity Using the Implicit Association Test and Self-Reports
}

\author{
Víctor Omar Corral-Frías ${ }^{1}$, Marc Yancy Lucas ${ }^{2}$, Nadia Saraí Corral-Frías ${ }^{1,2} \mathbb{D}$, \\ Víctor Corral-Verdugo ${ }^{1,2, *}$ and César Tapia-Fonllem ${ }^{2}$ \\ 1 Social Sciences Postgraduate Program, Universidad de Sonora, Hermosillo, Sonora 83000, Mexico; \\ victoriomar6@gmail.com (V.O.C.-F.); nadia.corral@unison.mx (N.S.C.-F.) \\ 2 Psychology Department, Universidad de Sonora, Hermosillo, Sonora 83000, Mexico; \\ mylucas@email.arizona.edu (M.Y.L.); cesar.tapia@unison.mx (C.T.-F.) \\ * Correspondence: victorcorral@sociales.uson.mx
}

Received: 11 July 2019; Accepted: 15 October 2019; Published: 21 October 2019

\begin{abstract}
Affinity towards diversity (ATD) is the tendency to appreciate the dynamic variety of biophysical and socio-cultural scenarios. ATD may reveal a human predisposition to conserve the diversity necessary to guarantee the preservation of human and natural ecosystems. This study expands upon previous studies which employed only self-report measures by introducing a version of the Implicit Association Test (IAT) and by using a mediational model to test whether ATD through sustainable (pro-environmental and pro-social) behaviors leads to greater wellbeing. We recruited 119 Mexican students to complete a computerized IAT task and respond to ATD, wellbeing, and sustainable behavior self-report questionnaires. Reliability analyses of the scales utilized showed acceptable indexes. A mediational model was tested to examine whether sustainable behaviors mediate the relationship between ATD and wellbeing. Results demonstrated that affinity towards diversity indirectly predicted wellbeing via the mediating effects of pro-environmental behaviors and altruism. Despite finding an association between self-reported affinity towards biodiversity and IAT reaction times, an association was not found with D scores, highlighting the need for further research. These findings suggest that those with increased inclination towards diversity are more prone to engage in environmentally (both physical and social) protective behaviors and to experience psychological wellbeing.
\end{abstract}

Keywords: IAT; affinity; diversity; wellbeing; sustainable behaviors; altruism

\section{Introduction}

The survival of humans and other species depends upon the homeostatic functioning of ecosystems, which allows for maintained access to drinkable water, breathable air, and productive soils. Ecosystems depend on an intricate balance of inorganic substrates and a huge diversity of plants and animals [1-3]. One of the challenges of environmental conservation in urban growth, agriculture, and industrialization is that native species are replaced by non-native species, disrupting the balance in natural ecosystems [4]. This replacement sometimes leads to the homogenization of biological beings, which threatens local ecosystems by reducing biological uniqueness [5]. The loss in biodiversity has been recognized as one of the most dangerous threats to the biosphere [6]. Similarly, socio-cultural diversity has been threatened by economic globalization and increased urbanization [7]. The extinction of spoken languages and vernacular traditions has become as common as the extinction of species in ecosystems [8,9].

A major concern associated with the loss of biological and social diversity is that it may lead to decreased human wellbeing, and that the reduction will likely disproportionately impact disadvantaged populations [2]. Decreased natural diversity may also impact reliable access to food, 
clean water, and raw materials. Conversely, it has been demonstrated that increased exposure to natural environments and contact with greater levels of biodiversity lead to higher levels of physical and psychological wellbeing [10,11]. Moreover, several studies suggest that social and cultural diversity promotes creativity and innovation, economic development, livability, competitiveness, resilience, and tolerance [12-14]. The practice of sustainable behaviors (i.e., actions aimed at protecting natural and social resources) also results in higher levels of psychological wellbeing [15].

A traditional perspective on the relationship between humans and the natural world views the latter as an inexhaustible and infinite resource that exists solely to satisfy the needs of the former [16]. However, Schultz et al. [17] argued that in order to achieve a sustainable environment it is necessary to establish a balance between resource consumption and the capacity of the natural environment to renew those resources. Recently, this ecological perspective has been developed further to encompass a vision of nature and natural diversity as a "positive environment" on equal footing with the satisfaction of human needs [18]. The model proposes that a positive environment is a context that promotes individual and collective benefits while simultaneously influencing human predispositions to conserve the socio-physical structures for the subsistence of life. The presence of diversity in the environment may be one of these influences.

Evidence suggests environmental conservation and the continued sustenance of a positive environment requires changes in human behavior $[19,20]$. Sustainable behaviors have been examined through macro-scale theories (e.g., sociopolitical influences) as well as psychological ones (e.g., the theory of planned behavior) to better inform programs aimed at environmental conservation and the protection of ecosystem diversity [21]. Furthermore, studies show that pro-ecological attitudes, knowledge about the environment, values, personal norms, ecological beliefs, and conservationist motives are linked to increased sustainable behaviors [21,22].

\section{Affinity towards Diversity}

Diversity plays a paramount role in the conservation of ecosystem integrity. Recent studies have focused on the influence of affinity towards diversity (ATD) on sustainable behaviors. ATD is defined "as a tendency to prefer diversity and variations in bio-physical and socio-cultural living scenarios" [23]. ATD can be conceptualized as a predisposition to appreciate the dynamic variety of interactions between humans and nature [24]. Empirical evidence has demonstrated that ATD is distinct from acceptance or tolerance for difference or diversity [23] and is likely an evolved mental trait that allows humans certain advantages in perceiving environmental opportunities [25]. As a collateral effect, this psychological tendency seemingly influences individual orientation towards environmental conservation [24]. ATD thus reflects a stable preference for natural and social diversity that humans encounter in their everyday environments. This preference includes affinity for physical (landscape, weather), biological (plants, animals), and social (ideological, ethnic, religions, hobbies, interests) diversity $[23,24,26]$.

A recent study examined the perception of biodiversity as a positive attribute in green urban spaces in two samples of participants (community members and expert ecologists). The results showed that both groups were able to correctly identify differences in biodiversity. The community sample demonstrated preference for natural environments but preferred half-open parks to areas of more complex vegetation. Ecological experts rated biodiverse sites as more positive, suggesting that such environmental knowledge has the potential to increase preference for biodiversity [27]. This could potentially provide an interesting avenue for intervention.

ATD has demonstrated positive association with self-reports of sustainable behaviors, indicating that greater preference for bio- and socio-diversity is associated with an increased commitment to engage in environmentally protective behaviors [23,24]. Sustainable behaviors constitute a set of actions aimed at protecting the socio-physical environment and include pro-ecological behaviors (actions aimed at conserving the natural environment), frugal behaviors (voluntary reduction of 
resource consumption), altruistic behaviors (actions aimed at supporting others in need), and equitable behaviors (fair treatment of others) [28].

ATD, in conjunction with other psychological factors, forms the basis for a pro-sustainability orientation, which in turn predicts sustainable behaviors [29]. Moreover, sustainable behaviors are reinforced by intrinsic rewards such as satisfaction, feelings of happiness, and wellbeing resulting from practicing such actions [15,30-32].

Previous ATD studies have depended solely on self-reported measurements. However, the low convergence between self-reported and objective behavior is a common criticism in the environmental psychology discourse [22]. Social desirability and other biases may encourage participants to over-represent their preference for bio- and socio-diversity based, in part, on the cultural acceptance of such diversity (or at least some of its components). This may lead to an overestimation of the actual degree of ATD. One account of the lack of congruence between self-report and objective behavior in the context of sustainable behaviors is dual-processing metatheory. This theory hypothesizes that two divergent social cognitions co-occur: the first comprises explicit conscious attitudes, which are reflected in the person's self-reports, and second are implicit attitudes that unconsciously influence behavior [33]. As such, the incorporation of the Implicit Association Test (IAT) may represent a more comprehensive measurement of affinity toward diversity.

The IAT provides a suitable methodological framework to study ATD since it can reduce deliberate "masking" predispositions and therefore reveal attitudes that participants may attempt to obfuscate. The IAT is one of the most commonly used tools in the study of implicit attitudes [34], and has been used in several investigations within pro-environmental psychology [35-37]. For instance, a recent study found positive relationships between implicit attitudes and recycling behavior. Beattie and McGuire found that implicit attitudes toward the environment were associated with unconscious patterns of eye movements in carbon-footprint-related images [38,39]. However, some more recent publications have found small-to-moderate or more nuanced relationships. For instance, Steiner and colleagues found low congruence between explicit and implicit sustainability orientations [40]. Moreover, although the literature is growing, the field of assessing affinity towards diversity or connectedness to nature is nascent, and factors that may affect behavioral outcomes (e.g., socioeconomic background or cultural differences) are still under investigation.

Given this previous research, the primary objective of this study was to investigate affinity towards diversity using two distinct methods: self-report and IAT. We hypothesized that due to the heterogeneity of the methods used there would be little-if any-convergence between self-report and IAT. We further examined the association between ATD and sustainable behaviors as well as the link between these behaviors and wellbeing. We hypothesized that higher affinity towards diversity would be associated with sustainable behaviors and that, in turn, these behaviors would predict wellbeing, implying that ATD has an indirect influence on wellbeing through sustainable behaviors.

\section{Method}

\subsection{Participants}

We recruited 119 undergraduate students at a public university in northwestern Mexico for this study (33.3\% male, $64.2 \%$ female, $1.6 \%$ did not answer). Participants were 18 years or older $(\mathrm{M}=21.1 \pm 2.4)$ from the Psychology and Nutrition departments. The average number of years of education was 14 (14.36 \pm 2.43 ). Most participants were single (95\% single, $3.4 \%$ married, and $1.7 \%$ living with a partner) and self-reported being part of the middle class $(75.4 \%)$. All participants were of Hispanic descent. Students were invited to participate in class with no exclusion criteria. No monetary compensation was provided. A short debriefing presentation was conducted afterwards to outline the objectives of the research project. 


\subsection{Instruments}

\subsubsection{Sustainable Behaviors}

Sustainable behavior was measured by two scales assessing pro-environmental and altruistic behaviors [28]. Pro-environmental behavior was measured using sixteen 4-point (never to always) Likert-type questions $(\alpha=0.73)$. Participants were asked to report their frequency of engagement in behaviors such as collecting and recycling used paper, buying products in refillable packages, and buying seasonal products (fruits and vegetables). The altruism scale comprised ten 4-point (never to always) Likert-type questions ( $\alpha=0.72$ ). Participants were asked to answer how often they engaged in behaviors such as giving away used clothes, donating blood, or helping elderly people cross the street.

\subsubsection{Wellbeing}

Psychological wellbeing was assessed using a previously validated scale based on Ryff's wellbeing instrument [41]. The scale included thirteen 5-point Likert-type agreement items ( 0 to 4$)$ with statements like "In general, I feel confident and positive with myself" ( $\alpha=0.85)$.

\subsubsection{Affinity Towards Diversity}

\section{Self-Report}

The ATD scale [23] is designed to measure fondness toward diversity of the bio-physical and socio-cultural environments using a 14 question Likert-type scale $(\alpha=0.70)$. Participants were asked to agree with statements ranging from 0 to 3 ("Does not apply to me" to "Applies to me completely."). The scale was divided into two main subscales focusing on biological and social diversity. Each scale consisted of seven items. Items for the biological diversity subscale included statements such as "I like many species of animals, not only a few of them" whereas the items for the social diversity subscale included statements such as "I enjoy being with people of every social class."

\section{Computerized Task}

The Implicit Association Test (IAT) was administered to participants using E-prime (Psychology Software Tools). Participants responded to IAT stimuli using a computer (keyboard, mouse, and monitor). The test consisted of a total of 48 trials, of which 24 were congruent and 24 incongruent. During each trial a fixation point appeared, followed by a prime, then a blank screen followed by a target figure. The prime figures were drawings of diverse (numerous and varied plant types) and non-diverse scenery, whereas the target figures were photographs of positive (e.g., traditionally cute) or negative (e.g., traditionally scary or unpleasant) animals (see Figure 1). Given that the diversity and non-diversity images were intended to assess preference for diversity, not complexity, in the landscape, we decided to use drawings rather than photographs to reduce unwanted visual information. Participants were instructed to press " $\mathrm{A}$ " or " $\mathrm{L}$ " on a keyboard in response to images, using their left or right hand respectively. The congruent trials instructed participants to press the " $\mathrm{A}$ " key for positive images and diverse scenery or the "L" key for negative images and non-diverse scenery (e.g., a single plant). The incongruent trials asked participants to press the " $\mathrm{A}$ " key for non-diverse scenery and positive images or the " $L$ " key for diverse scenery and negative images. Shorter response times for the compatible version were expected for subjects scoring high in affinity towards diversity. 


\section{Point of fixation}

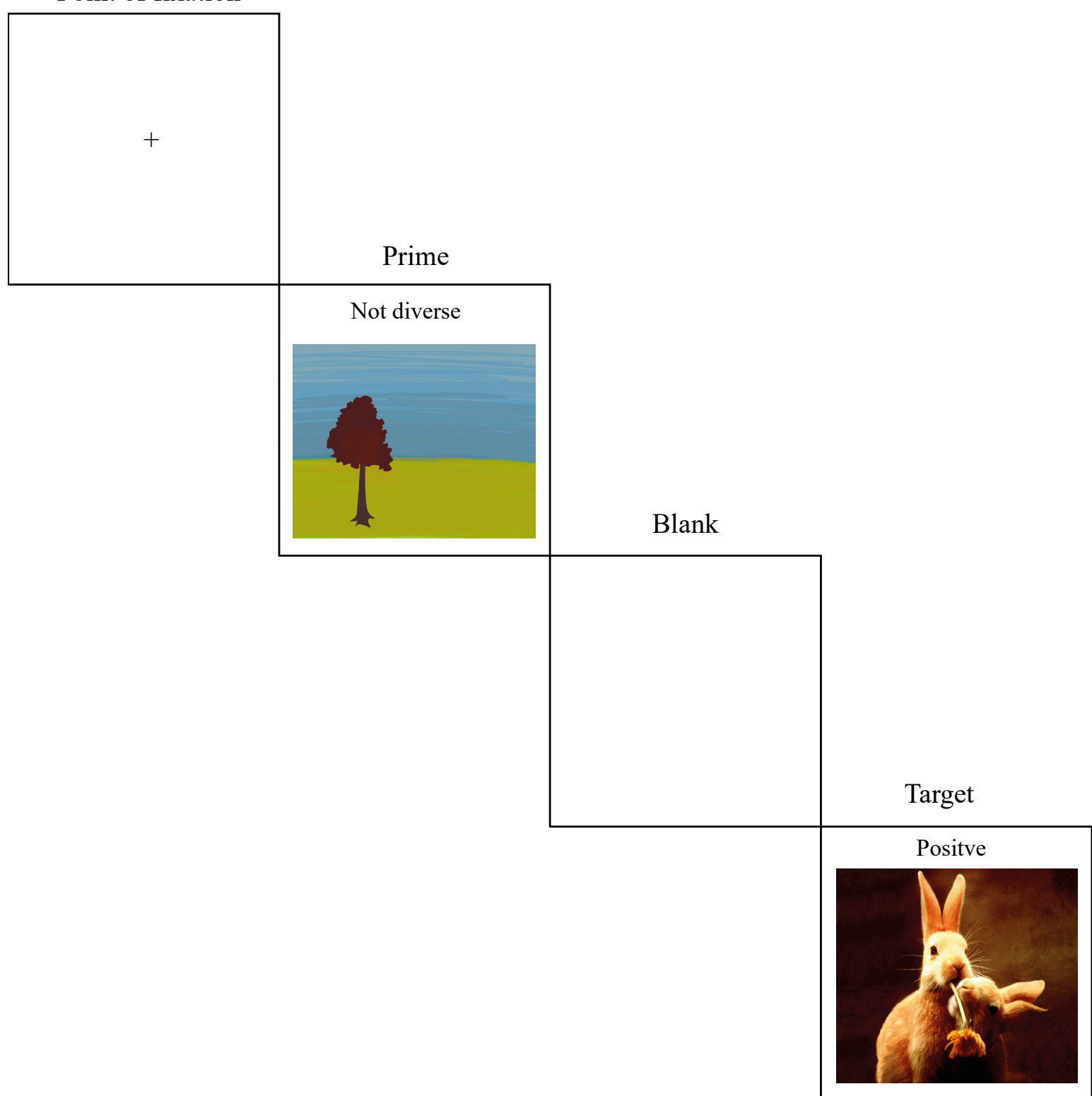

Figure 1. Depiction of a representative screenshot during the Implicit Association Test (IAT) task. Congruent trials instructed participants to press the " $\mathrm{A}$ " key for positive images and diverse scenarios or to press the "L" key for negative images and non-diverse scenarios. For incongruent trials, participants were instructed to press the " $\mathrm{A}$ " key to non-diverse scenarios and positive images or " $\mathrm{L}$ " key for diverse scenarios as well as negative images. The image shows a sample of an incongruent trial, where a non-diverse scenario was shown as a prime image after a fixation point. After a blank screen the target image was shown and participants were prompted to respond with a key press.

\section{Data Processing and Analysis}

\subsection{Data Cleaning and Processing}

For the IAT, reaction times below $200 \mathrm{~ms}$ and above 10,000 ms were not included in the analyses. A D score was computed by subtracting the mean reaction time of the incongruent trials from those in the incongruent trials and dividing this by the standard deviation of all the trials. 


\subsection{Data Analysis}

Univariate statistics were computed, as well as $t$-tests comparing reaction times to diverse and non-diverse stimuli in SPSS (version 21). Internal consistency and reliability analyses were conducted for each of the scales. A regression-based moderation model was tested using the PROCESS macro [42] for SPSS to examine main and indirect effects of affinity towards diversity on wellbeing via sustainable behaviors (See Figure 2 for model). PROCESS is a macro (computational) tool which simplifies the implementation of mediation, moderation, and conditional process analysis using manifest variables [43]. Every PROCESS estimate requires at least two regression equations and uses ordinary least squares regression to calculate the parameters of each equation. The theoretical model is shown in Figure 2.

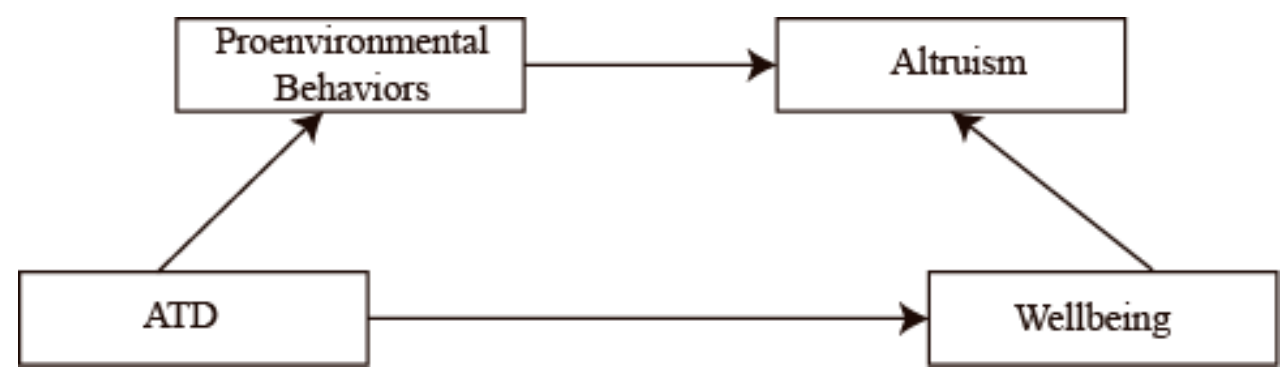

Figure 2. Theoretical model where higher affinity towards diversity (ATD) is associated with sustainable behaviors and, in turn, these behaviors will predict wellbeing.

\section{Results}

Table 1 summarizes the univariate statistics and reliability coefficients of the scales, and includes means, standard deviations, minimum and maximum values, as well as the corresponding values of Cronbach's alpha for each scale.

Table 1. Mean and standard deviation of each scale.

\begin{tabular}{cccccc}
\hline Scale & M & SD & Min & Max & A \\
\hline Affinity Towards Diversity & 2.25 & 0.31 & 1.50 & 2.86 & 0.69 \\
Affinity Towards Biodiversity & 3.11 & 0.54 & 1.83 & 4.00 & 0.67 \\
\hline Sustainable Behaviors & & & & & \\
\hline Pro-ecological behaviors & 2.63 & 0.37 & 1.94 & 3.38 & 0.72 \\
Altruism & 2.65 & 0.42 & 1.40 & 3.80 & 0.72 \\
\hline Psychological Well-Being & 2.14 & 0.29 & 1.10 & 2.54 & 0.85 \\
\hline
\end{tabular}

The IAT effect, produced by subtracting the mean score for Biodiversity/Positive blocks $(\mathrm{M}=833.32 \pm 317.63)$ from the mean score for the No biodiversity/Positive blocks $(\mathrm{M}=1278.58 \pm 643.81)$, was $445.26( \pm 539.05 ; \mathrm{N}=122)$, suggesting an implicit tendency for associating biodiversity with positive attributes (See Figure 3). According to the literature, an IAT effect of 0 would indicate no association, and a negative IAT effect in this context would indicate a general tendency to associate a lack of biodiversity with positive features [34]. The results show a significant difference between reaction times in these two different types of trials ( $\mathrm{t} 121=-9.12, p<0.0001)$. To reduce the effects of outliers, the IAT scores were log transformed. These differences remained even when they were $\log$ transformed $(\mathrm{t} 121=-13.60, p<0.0001)$. 


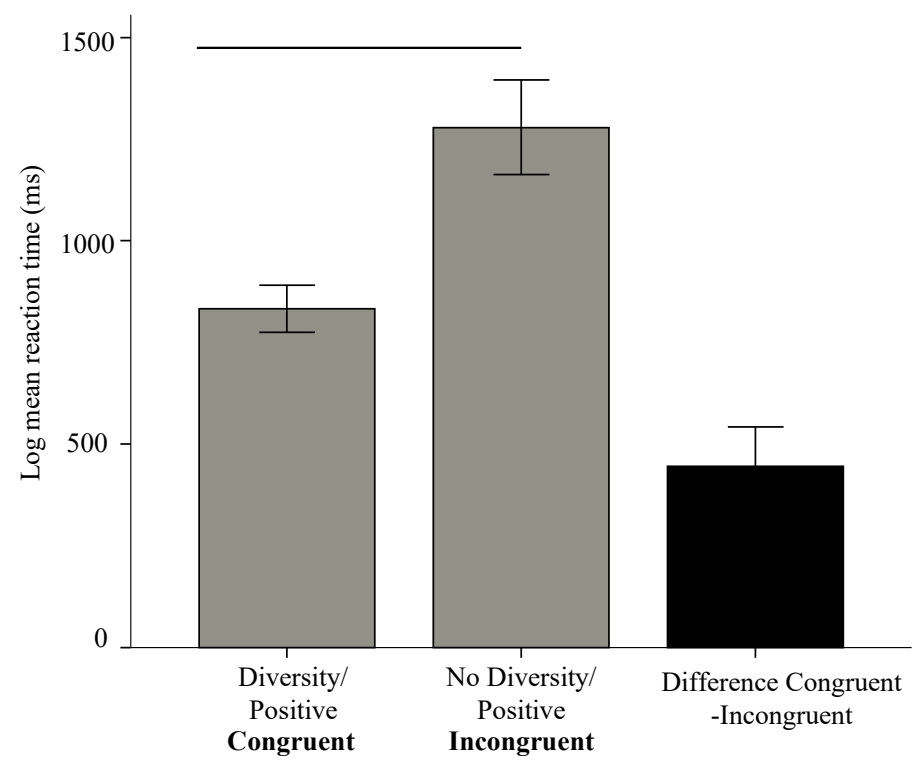

Figure 3. There was a significant difference between the mean reaction time in Biodiversity/Positive blocks $(\mathrm{M}=833.32 \pm 317.63)$ and No biodiversity/Positive blocks $(\mathrm{M}=1278.58 \pm 643.81)$. In black, IAT effect produced by subtracting the mean score for Biodiversity/Positive blocks $445.26 \pm 539.05$.

We did not find a significant association between IAT effect (log and non-log transformed) and any self-report measures of ATD $(p>0.2)$. The association became trending with only nature-related ATD (ATDBio) items $(p>0.1)$. Additionally, D scores were not associated with self-reported measures of ATD. We did find a significant negative association between both incongruent reaction times and ATDBio (Diversity/Negative: $\mathrm{r}=-0.207, p=0.02$; No Diversity/Positive: $\mathrm{r}=-0.196, p=0.03$ ), suggesting the longer it takes participants to react to an incongruent trial, the less they self-report affinity to natural environment diversity (Figure 4).

A

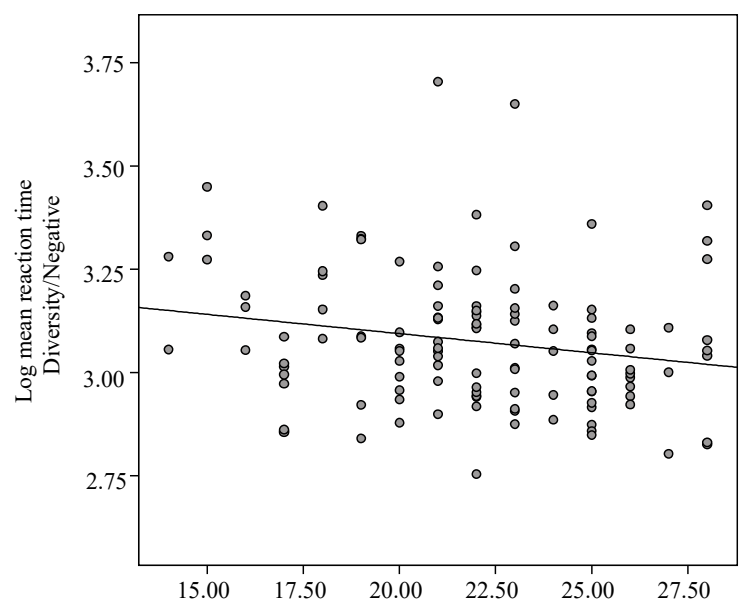

Affinity towards diversity: Biological
$\mathrm{B}$

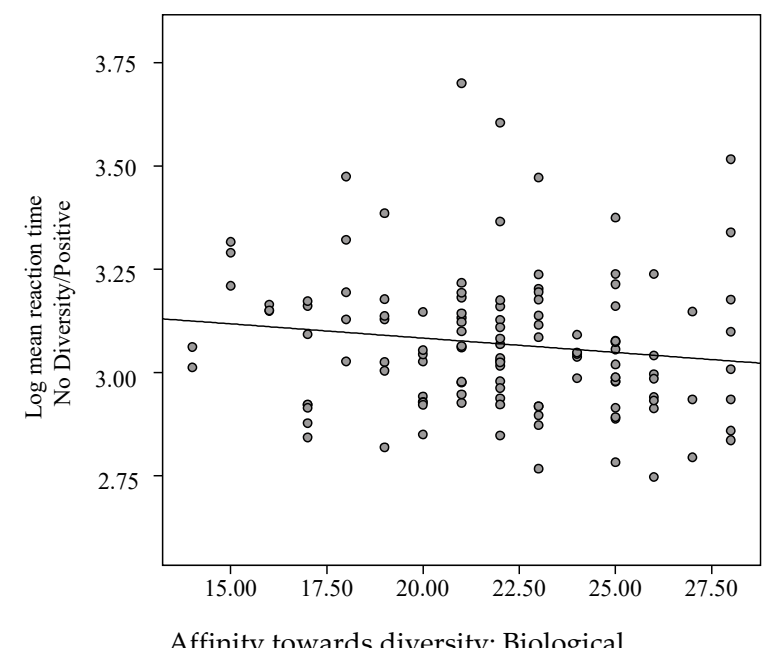

Affinity towards diversity: Biological

Figure 4. Significant association between both incongruent reaction times and ATD (biological).

(A) Diversity/Negative: $\mathrm{r}=-0.207, p=0.02$; (B) No Diversity/Positive: $\mathrm{r}=-0.196, p=0.03$.

The model demonstrated that affinity towards diversity indirectly predicted wellbeing via the mediating effects of pro-environmental and altruistic behaviors. The model suggests that those who report affinity towards diversity tend to report higher involvement in pro-environmental and altruistic 
behaviors, and these in turn predict wellbeing. This was true for affinity towards diversity, including both biodiversity and social diversity (Figure 5A) as well as biodiversity independently (Figure 5B).

A

Indirect effect: 0.023

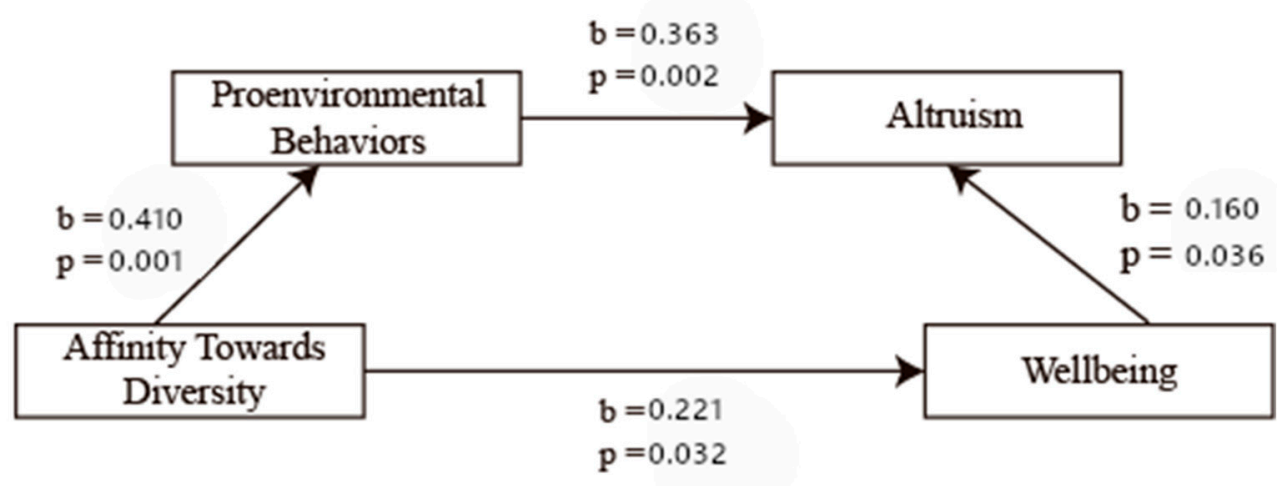

B

Indirect effect $=0.025$

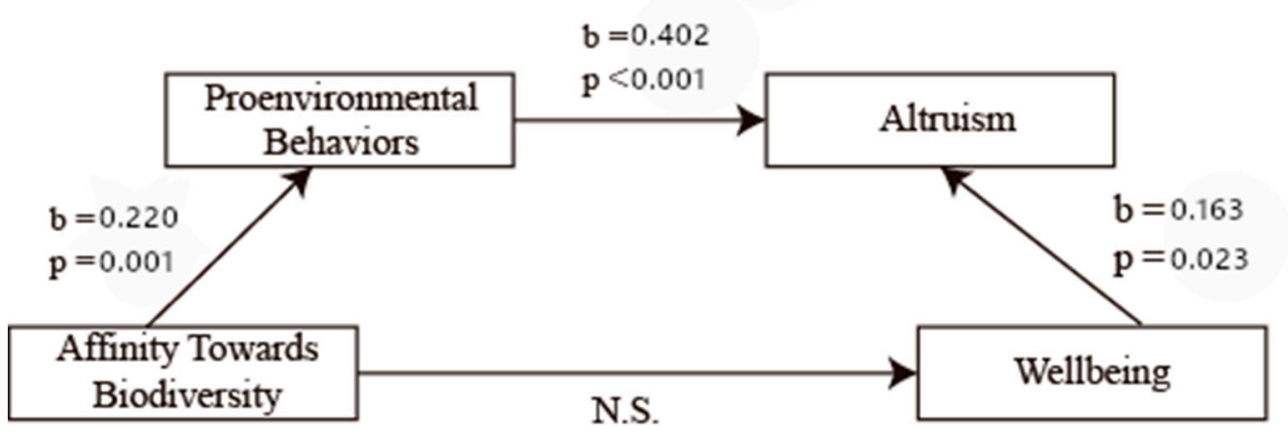

Figure 5. Mediational model demonstrating that higher affinity towards diversity (A; indirect effect $=0.025)$ and biodiversity $(\mathbf{B}$; indirect effect $=0.023)$ is indirectly associated with wellbeing via pro-environmental behaviors and altruism.

\section{Discussion}

Our study reinforces previous evidence for an association between ATD, sustainable behaviors, and wellbeing. The results suggest that those with increased affinity towards both biological and social diversity report increased sustainable behaviors (pro-environmental and altruistic behavior) and, in turn, wellbeing. We further provide some evidence of convergence between self-reported ATD and affinity towards diversity as indicated by reaction time.

The results show significant differences between the diversity congruent trials and no diversity incongruent trials (Figure 3). These differences created a positively balanced IAT effect, which suggests an implicit tendency for associating biodiversity with positive attributes, which replicates the findings of Qiu et al. [27].

We further show some limited evidence of convergence between explicit and implicit ATD. Although we did not find a direct association between the IAT effect and self-reported ATD, we found an association between incongruent trials and self-reported affinity towards biological diversity (Figure 4). The limited convergence may be due to limitations in our study (see below) or discrepancies between self-report and reaction time. Likewise, some studies have not demonstrated an association 
between implicit and explicit measures in personality assessments [40]. Research has also found that biases such as social desirability moderate the relationship between implicit and explicit measures [44].

The results presented here suggest that ATD has an indirect effect on wellbeing through sustainable behaviors (See Figure 5). There is extensive evidence providing support for the beneficial benefits of natural environments on human health [21,25,45-47]. Those benefits expand to biodiversity's positive influence on human health [10]. For instance, a study of more than 3000 Japanese seniors found that the best predictor of 5-year survival was proximity to walkable green spaces [48]. This suggests humans value nature and biodiversity due to the potential psychobiophysical benefits they provide [49-51]. Authors such as Frumkin [25] suggest that human appreciation for diversity emerged as an adaptive tendency developed after the positive impacts it produced, such as survival or general wellbeing. More recent views propose that wellbeing may emerge from positive environments where the conservation of the environment is as important as the satisfaction of human needs [16]. These views provide a theoretical foundation for our model, where ADT is associated with wellbeing through sustainable behaviors. Our model results also suggest that the presence of diversity may be considered as an important component of a positive environment, since this contextual feature stimulates both environmental conservation and wellbeing.

This study is not without limitations. Firstly, the sample was homogeneous (comprised of undergraduate students) and the sample size was modest. Thus, these results may not be generalizable to the general population. The association between IAT measures and self-reported ATD was only trending with some variables, which may be attributable to low statistical power due to our sample size. It may also be due to internal consistency reliability statistics with limited acceptability. Further, the IAT only included depictions of biological diversity. Only after self-reported ATD was divided into social and biological subscales were associations found, However, divergences between IAT (implicit) and self-report (explicit) has been demonstrated when self-reports are inaccurate due to response bias, while implicit measures are thought to be less affected [34]. Further research is needed to elucidate this phenomenon.

These limitations highlight new areas of opportunity in the use of novel multimethod designs to investigate ATD. It would be useful to collect data from a larger community sample for generalizability. Given that the ATD scale can be separated into two components (i.e., affinity towards social and biological diversity), we propose to construct a more comprehensive affinity towards diversity scale that includes the two major subscales: social and biological diversity. Likewise, due to the importance of social diversity, implicit measures should also include blocks reflecting this type of diversity. Finally, it is important that this research is conducted in diverse cultural and socioeconomic samples in order to assess possible differences due to these variables. The current investigation also adds to the growing evidence of concerns in the design and interpretation of the IAT [52]. A recent study showed evidence for participant awareness in their IAT response latencies. More importantly, they were able to accurately recognize the features within the task that produced those behaviors. Moreover, the validity of this awareness predicted their test scores. The authors suggest that these results challenge the claim to attitude effects of which individuals are unaware [53]. These reports and our results call attention to the need of new experimental designs to assess ATD and other environmental attitudes and behaviors.

Our results have both basic and applied implications. Given that biodiversity not only stimulates physical wellbeing by providing access to food, clean air, and water but also psychological wellbeing, it is important to study its correlates. Research conducted by ecologists, health and social scientists, and planners should guide the development of policies and land use [11]. These policies should help promote human interaction with biological and social diversity, which holds promise to improve environmental conditions as well as human physical and psychological wellbeing.

Author Contributions: Conceptualization, V.O.C.-F.; Formal analysis, V.O.C.-F.; Funding acquisition, V.O.C.-F.; Investigation, V.O.C.-F.; Methodology, M.Y.L. and V.C.-V.; Project administration, C.T.-F.; Software, M.Y.L.; Supervision, N.S.C.-F. and V.C.-V.; Validation, N.S.C.-F.; Writing-original draft, V.C.-V.; Writing-review and editing, M.Y.L., N.S.C.-F., V.C.-V., and C.T.-F. 
Funding: This research received no external funding.

Acknowledgments: We extend thanks to the all the students who participated in the study. VOCF and MYL were supported by the Mexican Council of Science and Technology (CONACyT).

Conflicts of Interest: The authors declare that they have no conflicts of interest. All procedures performed in studies involving human participants were in accordance with the ethical standards of the institutional and/or national research committee and with the 1964 Helsinki declaration and its later amendments or comparable ethical standards. All individual participants included in the study provided informed consent.

\section{References}

1. DeFries, R.; Hansen, A.; Turner, B.L.; Reid, R.; Liu, J. Land Use Change Around Protected Areas: Management to Balance Human Needs and Ecological Function. Ecol. Appl. 2007, 17, 1031-1038. [CrossRef] [PubMed]

2. Díaz, S.; Fargione, J.; Chapin, F.S.; Tilman, D. Biodiversity Loss Threatens Human Well-Being. PLoS Biol. 2006, 4, e277. [CrossRef] [PubMed]

3. Hooper, D.U.; Chapin, F.S.; Ewel, J.J.; Hector, A.; Inchausti, P.; Lavorel, S.; Lawton, J.H.; Lodge, D.M.; Loreau, M.; Naeem, S.; et al. Effects of Biodiversity on Ecosystem Functioning: A Consensus of Current Knowledge. Ecol. Monogr. 2005, 75, 3-35. [CrossRef]

4. McKinney, M.L. Urbanization, Biodiversity, and ConservationThe impacts of urbanization on native species are poorly studied, but educating a highly urbanized human population about these impacts can greatly improve species conservation in all ecosystems. BioScience 2002, 52, 883-890. [CrossRef]

5. Blair, R.B. Birds and Butterflies Along Urban Gradients in Two Ecoregions of the United States: Is Urbanization Creating a Homogeneous Fauna? In Biotic Homogenization; Lockwood, J.L., McKinney, M.L., Eds.; Springer US: Boston, MA, USA, 2001; pp. 33-56. ISBN 978-1-4615-1261-5.

6. Wilson, E.O. Questions of Science. In The Diversity of Life, 1st ed.; Belknap Press of Harvard University Press: Cambridge, MA, USA, 2010; ISBN 978-0-674-05817-0.

7. Tonn, B.E. Futures sustainability. Futures 2007, 39, 1097-1116. [CrossRef]

8. Jimeno, M.; Sotomayor, M.L.; Valderrama, L.M. Chocó: Diversidad Cultural y Medio Ambiente, 1st ed.; Fondo FEN: Bogotá, Colombia, 1995; ISBN 978-958-9129-30-2.

9. Nettle, D.; Romaine, S. Vanishing Voices: The Extinction of the World's Languages; Oxford Univ. Press: Oxford, UK, 2002; ISBN 978-0-19-515246-3.

10. Brown, C.; Grant, M. Biodiversity and Human Health: What Role for Nature in Healthy Urban Planning? Built Environ. 2005, 31, 326-338. [CrossRef]

11. Sandifer, P.A.; Sutton-Grier, A.E.; Ward, B.P. Exploring connections among nature, biodiversity, ecosystem services, and human health and well-being: Opportunities to enhance health and biodiversity conservation. Ecosyst. Serv. 2015, 12, 1-15. [CrossRef]

12. Crisp, R.J.; Turner, R.N. Cognitive adaptation to the experience of social and cultural diversity. Psychol. Bull. 2011, 137, 242-266. [CrossRef]

13. Florida, R. Megaregions: the importance of place. Harvard Business Review, 1 March 2008.

14. Qian, H.; Ács, Z.J.; Stough, R.R. Regional systems of entrepreneurship: The nexus of human capital, knowledge and new firm formation. In Global Entrepreneurship, Institutions and Incentives; Edward Elgar Publishing: Cheltenham, UK, 2015; pp. 257-285. ISBN 978-1-78471-805-3.

15. Corral Verdugo, V.; Montiel-Carvajal, M.; Sotomayor-Petterson, M.M.; Frias-Armenta, M.; Tapia-Fonllem, C.; Fraijo-Sing, B. Psychological wellbeing as correlate of sustainable behaviors. In Psychology Research Progress. Recent Hispanic Research on Sustainable Behavior and Interbehavioral Psychology; Garcia, C., Corral Verdugo, V., Moreno, D., Eds.; Nova Science Publishers: Hauppauge, NY, USA, 2013; pp. 27-40.

16. Arcury, T.A.; Johnson, T.P.; Scollay, S.J. Ecological Worldview and Environmental Knowledge: The “New Environmental Paradigm". J. Environ. Educ. 1986, 17, 35-40. [CrossRef]

17. Schultz, P.W. Inclusion with Nature: The Psychology Of Human-Nature Relations. In Psychology of Sustainable Development; Schmuck, P., Schultz, W.P., Eds.; Springer US: Boston, MA, USA, 2002; pp. 61-78. ISBN 978-1-4615-0995-0.

18. Corral-Verdugo, V.; Frías-Armenta, M. The sustainability of positive environments. Environ. Dev. Sustain. 2016, 18, 965-984. [CrossRef] 
19. Bennett, N.J.; Roth, R.; Klain, S.C.; Chan, K.; Christie, P.; Clark, D.A.; Cullman, G.; Curran, D.; Durbin, T.J.; Epstein, G.; et al. Conservation social science: Understanding and integrating human dimensions to improve conservation. Biol. Conserv. 2017, 205, 93-108. [CrossRef]

20. Steg, L.; Vlek, C. Encouraging pro-environmental behaviour: An integrative review and research agenda. J. Environ. Psychol. 2009, 29, 309-317. [CrossRef]

21. Gifford, R.; Nilsson, A. Personal and social factors that influence pro-environmental concern and behaviour: A review: Personal and Social Factors That Influence Pro-Environmental Behaviour. Int. J. Psychol. 2014, 49, 141-157. [CrossRef] [PubMed]

22. Kollmuss, A.; Agyeman, J. Mind the Gap: Why do people act environmentally and what are the barriers to pro-environmental behavior? Environ. Educ. Res. 2002, 8, 239-260. [CrossRef]

23. Corral-Verdugo, V.; Bonnes, M.; Tapia-Fonllem, C.; Fraijo-Sing, B.; Frías-Armenta, M.; Carrus, G. Correlates of pro-sustainability orientation: The affinity towards diversity. J. Environ. Psychol. 2009, 29, 34-43. [CrossRef]

24. Bonnes, M.; Carrus, G.; Corral-Verdugo, V.; Passafaro, P. The socio-psychological affinity towards diversity: From biodiversity to socia-ecological sustainability. In Psychological Approaches to Sustainability: Current Trends in Theory, Research and Applications; Nova Science Publishers: Hauppauge, NY, USA, 2013.

25. Frumkin, H. Beyond toxicity: Human health and the natural environment. Am. J. Prev. Med. 2001, 20, 234-240. [CrossRef]

26. Blokland, T.; van Eijk, G. Do People Who Like Diversity Practice Diversity in Neighbourhood Life? Neighbourhood Use and the Social Networks of 'Diversity-Seekers' in a Mixed Neighbourhood in the Netherlands. J. Ethn. Migr. Stud. 2010, 36, 313-332. [CrossRef]

27. Qiu, L.; Lindberg, S.; Nielsen, A.B. Is biodiversity attractive?-On-site perception of recreational and biodiversity values in urban green space. Landsc. Urban Plan. 2013, 119, 136-146. [CrossRef]

28. Tapia-Fonllem, C.; Corral-Verdugo, V.; Fraijo-Sing, B.; Durón-Ramos, M. Assessing Sustainable Behavior and its Correlates: A Measure of Pro-Ecological, Frugal, Altruistic and Equitable Actions. Sustainability 2013, 5 , 711-723. [CrossRef]

29. Corral-Verdugo, V.; Frías-Armenta, M.; García-Cadena, C. Introduction to the psychological dimensions of sustainability. In Psychological Approaches to Sustainability; Nova Science Publishers: New York, NY, USA, 2010; pp. 3-18.

30. Brown, K.W.; Kasser, T. Are Psychological and Ecological Well-being Compatible? The Role of Values, Mindfulness, and Lifestyle. Soc. Indic. Res. 2005, 74, 349-368. [CrossRef]

31. De Young, R. Some Psychological Aspects of Reduced Consumption Behavior: The Role of Intrinsic Satisfaction and Competence Motivation. Environ. Behav. 1996, 28, 358-409. [CrossRef]

32. Kaida, N.; Kaida, K. Pro-environmental behavior correlates with present and future subjective well-being. Environ. Dev. Sustain. 2016, 18, 111-127. [CrossRef]

33. Greenwald, A.G.; Banaji, M.R. Implicit social cognition: Attitudes, self-esteem, and stereotypes. Psychol. Rev. 1995, 102, 4-27. [CrossRef] [PubMed]

34. Greenwald, A.G.; McGhee, D.E.; Schwartz, J.L. Measuring individual differences in implicit cognition: The implicit association test. J. Pers. Soc. Psychol. 1998, 74, 1464-1480. [CrossRef] [PubMed]

35. Schultz, P.W.; Shriver, C.; Tabanico, J.J.; Khazian, A.M. Implicit connections with nature. J. Environ. Psychol. 2004, 24, 31-42. [CrossRef]

36. Geng, L.; Xu, J.; Ye, L.; Zhou, W.; Zhou, K. Connections with Nature and Environmental Behaviors. PLoS ONE 2015, 10, e0127247. [CrossRef]

37. Levine, D.S.; Strube, M.J. Environmental Attitudes, Knowledge, Intentions and Behaviors Among College Students. J. Soc. Psychol. 2012, 152, 308-326. [CrossRef]

38. Beattie, G.; McGuire, L. The Modifiability of Implicit Attitudes to Carbon Footprint and Its Implications for Carbon Choice. Environ. Behav. 2018, 0013916518808571. [CrossRef]

39. Beattie, G.; McGuire, L. Harnessing the unconscious mind of the consumer: How implicit attitudes predict pre-conscious visual attention to carbon footprint information on products. Semiotica 2015, 2015, 253-290. [CrossRef]

40. Steiner, G.; Geissler, B.; Schreder, G.; Zenk, L. Living sustainability, or merely pretending? From explicit self-report measures to implicit cognition. Sustain. Sci. 2018, 13, 1001-1015. [CrossRef]

41. Ryff, C. Happiness Is Everything, or Is It? Explorations on the Meaning of Psychological Well-Being. J. Pers. Soc. Psychol. 1989, 57, 1069-1081. [CrossRef] 
42. Hayes, A.F. Introduction to mediation, moderation, and conditional process analysis: A regression-based approach. In Methodology in the Social Sciences; The Guilford Press: New York, NY, USA, 2013; ISBN 978-1-60918-230-4.

43. Hayes, A.F.; Montoya, A.K.; Rockwood, N.J. The analysis of mechanisms and their contingencies: PROCESS versus structural equation modeling. Australas. Mark. J. AMJ 2017, 25, 76-81. [CrossRef]

44. Karpinski, A.; Hilton, J.L. Attitudes and the Implicit Association Test. J. Pers. Soc. Psychol. 2001, 81, 774-788. [CrossRef] [PubMed]

45. van den Bosch, M. Natural Environments, Health, and Well-Being. Oxf. Res. Encycl. Environ. Sci. 2017. [CrossRef]

46. Guite, H.F.; Clark, C.; Ackrill, G. The impact of the physical and urban environment on mental well-being. Public Health 2006, 120, 1117-1126. [CrossRef]

47. Maller, C.; Townsend, M.; Pryor, A.; Brown, P.; St Leger, L. Healthy nature healthy people: 'contact with nature' as an upstream health promotion intervention for populations. Health Promot. Int. 2006, 21, 45-54. [CrossRef]

48. Takano, T.; Nakamura, K.; Watanabe, M. Urban residential environments and senior citizens' longevity in megacity areas: The importance of walkable green spaces. J. Epidemiol. Community Health 2002, 56, 913-918. [CrossRef]

49. Kellert, S.R. The Value of Life: Biological Diversity and Human Society; Island Press: Washington, DC, USA; Shearwater Books: Covelo, CA, USA, 1997; ISBN 978-1-55963-318-5.

50. Simaika, J.P.; Samways, M.J. Biophilia as a Universal Ethic for Conserving Biodiversity. Conserv. Biol. 2010, 24, 903-906. [CrossRef]

51. Greenwald, A.G.; Farnham, S.D. Using the implicit association test to measure self-esteem and self-concept. J. Pers. Soc. Psychol. 2000, 79, 1022-1038. [CrossRef]

52. Mitchell, G.; Tetlock, P. Popularity as a Poor Proxy for Utility: The Case of Implicit Prejudice; Social Science Research Network: Rochester, NY, USA, 2017.

53. Wilson, T.L.; Smith, T.H. Implicit Environmental Attitudes: Critique and Technique to Promote Awareness. IAFOR J. Psychol. Behav. Sci. 2017, 3, 11-22. [CrossRef]

(C) 2019 by the authors. Licensee MDPI, Basel, Switzerland. This article is an open access article distributed under the terms and conditions of the Creative Commons Attribution (CC BY) license (http://creativecommons.org/licenses/by/4.0/). 